\title{
Offline Consequences of Echo Chambers
}

\author{
Nynke M. D. Niezink \\ Carnegie Mellon University \\ Department of Statistics and Data Science \\ Pittsburgh, PA, USA \\ nniezink@andrew.cmu.edu
}

\begin{abstract}
Echo chambers exist both online and offline, and in both situations they can affect individuals' opinions and behavior. There is a need for an assessment of the relative strength of online and offline echo chambers, and their interaction, on offline consequences.
\end{abstract}

\section{CCS CONCEPTS}

- Networks $\rightarrow$ Online social networks; • Human-centered computing $\rightarrow$ Social network analysis; • Applied computing $\rightarrow$ Law, social and behavioral sciences; Sociology;

\section{KEYWORDS}

Social media; echo chambers; offline behavior.

\section{ACM Reference Format:}

Nynke M. D. Niezink. 2019. Offline Consequences of Echo Chambers. In Fourth International Workshop on Social Sensing (SocialSense'19), April 15, 2019, Montreal, QC, Canada. ACM, New York, NY, USA, 1 page. https://doi. org $/ 10.1145 / 3313294.3313381$

The Internet, through its abundance of social media platforms, has provided individuals with the possibility to connect with many more people than they could have connected with offline. While in theory this would allow individuals to be exposed to a greater variation of opinions and ideas, in practice they tend to form likeminded communities online.

This phenomenon, where a diverse, heterogeneous (online) population segregates into local network neighborhoods that consist of homogeneous individuals, is known as echo chamber formation [1]. In echo chambers, like-minded individuals almost exclusively interact with each other, leading to the reinforcement or amplification of ideas and beliefs through repeated contact.

Online echo chambers are often considered a threat to open and productive civic discourse, and a source of polarization. Moreover, major offline events have been attributed to the workings of echo chambers. Examples include the election of Donald Trump as US president and the UK referendum vote to leave the EU in 2016.

Over the last few years, the existence and origin of echo chambers have received a lot of academic and public attention. The amount of available data on this topic has certainly contributed

Permission to make digital or hard copies of all or part of this work for personal or classroom use is granted without fee provided that copies are not made or distributed for profit or commercial advantage and that copies bear this notice and the full citation on the first page. Copyrights for components of this work owned by others than the author(s) must be honored. Abstracting with credit is permitted. To copy otherwise, or republish, to post on servers or to redistribute to lists, requires prior specific permission and/or a fee. Request permissions from permissions@acm.org.

SocialSense'19, April 15, 2019, Montreal, QC, Canada

(c) 2019 Copyright held by the owner/author(s). Publication rights licensed to ACM. ACM ISBN 978-1-4503-6706-6/19/04 . \$ \$15.00

https://doi.org/10.1145/3313294.3313381 to its popularity among academics. Since most data sources are restricted to the online behavior of individuals, the relation of echo chambers to offline behavior and offline consequences mostly remains implicit. However, both old and new work suggests that this relation asks for further investigation:

- It is a well-established result that also in offline situations people segregate in homogeneous groups. Lazarsfeld and Merton [2] used the term homoplily to indicate the principle that more contact occurs between similar than between dissimilar people. Since then, many sociological studies have observed this phenomenon, in various contexts [3].

- Although political polarization in the US has increased in recent decades, polarization has increased the most among the demographic groups least likely to use the Internet and social media [4]. This finding suggests that the effect of online behavior, and that of echo chambers, on the recent increase in political polarization may be limited.

Both online and offline echo chambers can affect individuals' opinions and behavior. There is a need for an assessment of 1) the relative strength of these effects, 2) the interaction between online and offline echo chambers, and 3) how this interaction affects individual behavior. For example, it may well be that echo chambers in offline social networks have a stronger effect on political polarization than those in online social networks. In offline situations individuals have fewer opportunities to interact with different ideas. This would explain the comparative increase in polarization in demographic groups with little social media use.

Studies explicitly taking into account the effects of online and offline interactions in echo chambers on individuals' opinions and behavior could have strong policy implications. They could, for example, shed light on what platforms are suitable for preventing polarization due to pure homophilous interactions.

\section{REFERENCES}

[1] Cass R. Sunstein. 2001. Echo chambers: Bush v. Gore, impeachment, and beyond. Princeton University Press, Princeton, NJ.

[2] P. F. Lazarsfeld and R. K. Merton. 1954. Friendship as a social process: a substantive and methodological analysis. In Freedom and Control in Modern Society. M. Berger, editor. Van Nostrand, New York, 18-66.

[3] M. McPherson, L. Smith-Lovin, and J. M. Cook. 2001. Birds of a feather: Homophily in social networks. Annual Review of Sociology, 27, 414-444.

[4] Levi Boxell, Matthew Gentzkow, and Jesse M. Shapiro. 2017. Greater internet use is not associated with faster growth in political polarization among us demographic groups. PNAS, 114, 40, 10612-10617. 